\title{
Listeria monocytogenes: Vieja bacteria, desafío permanente
}

\author{
Listeria monocytogenes: Old bug, permanent challenge
}

Listeria monocytogenes es una bacteria ampliamente distribuida en la naturaleza. La listeriosis se considera una zoonosis, aunque la mayoría de las infecciones se producen en forma indirecta por contaminación de productos animales o vegetales ingeridos sin un procesamiento que permita eliminar el agente.

A pesar de ser una bacteria ubicua y de alta resistencia a condiciones ambientales adversas, es un patógeno poco frecuente en la población general, atacando de preferencia a personas en edades extremas de la vida, mujeres embarazadas y pacientes inmunodeprimidos.

Aunque en 1953 se reconoció la participación de un alimento en la transmisión de la enfermedad ${ }^{1}$, el primer brote de listeriosis relacionado a alimentos fue comunicado en $1983^{2}$. La investigación de este brote, detectado con relación a un aumento de casos perinatales, demostró que el causante fue repollo contaminado con deposiciones de ovejas infectadas. A partir de ese momento, L. monocytogenes se ha convertido en una más de las enfermedades infecciosas transmitidas por alimentos ${ }^{3}$.

Nuestro país no ha estado alejado de esta realidad y aunque la vigilancia de este agente infeccioso no se realiza en alimentos para consumo interno, sí se han hecho estudios que muestran su presencia en helados, quesos blandos, cecinas y mariscos ${ }^{4}$.

Este número de Revista Chilena de Infectología, incluye tres interesantes artículos sobre L. monocytogenes, comunicados muy oportunamente para informarnos de un problema sanitario en curso. Con fines didácticos, se ha incluido además, en la sección Retrato Microbiológico, una semblanza de este patógeno, efectuada por Dona Benadof ${ }^{5}$, y como broche de oro, la usual Nota Histórica, esta vez de W. Ledermann, sobre la figura de Joseph Lister ${ }^{6}$.

En el primer trabajo original, Rossi $\mathrm{L}$ y $\operatorname{cols}^{7}$ de la Facultad de Medicina de la Universidad de Buenos Aires, realizan una completa revisión de los brotes debidos a L. monocytogenes. En ella, se separan en brotes asociados a leche, queso y alimentos no lácteos. De esta interesante revisión se derivan recomendaciones de consumo de alimentos susceptibles de contaminación en población de riesgo y se sugiere que los casos esporádicos de infección son, al igual que los brotes, explicados por contaminación de alimentos. La experiencia norteamericana y europea ${ }^{8}$, muestra que un esfuerzo sanitario puede disminuir en forma significativa la tasa de enfermedad.

Larraín D y cols, de la Pontificia Universidad Católica de Chile ${ }^{9}$, informan sobre cuatro mujeres embarazadas infectadas por L. monocytogenes de un total de 16 casos ocurridos en ese centro entre los años 2001 y 2005. Sólo una de las pacientes tenía un factor de riesgo para infección agregado a la gestación (uso de corticosteroides por colitis ulcerosa). Destaca en esta serie, un caso de embarazo complicado con una meningitis por listeria y sin evidencias de infección ovular, situación infrecuentemente reportada en la literatura ${ }^{10}$ y primer caso comunicado en Chile.

Finalmente, nuestro grupo de trabajo en Clínica Alemana de Santiago- Noriega y cols ${ }^{11}$, reporta 10 infecciones por L. monocytogenes entre enero y julio de este año, de los cuales siete corresponden a mujeres embarazadas. En esta serie destaca que todas las pacientes reportadas son primigestas, con edades entre 25 y 31 años, sin factores de riesgo asociados y que viven en comunas del sector oriente de la capital. Los autores plantean este factor común como un patrón de riesgo para adquirir la enfermedad, suponiendo condiciones de vida y alimentación similar.

Las tres comunicaciones incluidas en esta revista, dan cuenta de un problema sanitario que en las últimas semanas ha causado alarma en la comunidad médica y la opinión pública de nuestro país. La reglamentación sanitaria nacional no exige notificación obligatoria en los casos de infección por este agente, pero si deben enviarse las cepas al Laboratorio de Microbiología del Instituto de Salud Pública de Chile (ISP) para su confirmación. La no existencia de normas de vigilancia para L. monocytogenes en los alimentos de consumo interno en Chile ${ }^{12}$, coloca a nuestra población predispuesta, en una situación de vulnerabilidad no acorde con el desarrollo económico y social de nuestro país.

En conferencia de prensa el pasado día jueves 21 de agosto del 2008, el ISP informo que hasta esa fecha habían recibido 79 cepas de L. monocytogenes, sin aclarar si se trataba de muestras o pacientes ${ }^{13}$. Este número, supera ampliamente las aproximadamente 50 cepas anuales recibidas en un año normal. Probable- 
mente faltan elementos para catalogar la situación de brote, para lo cual el análisis de la información debe ser más completo, pero es suficiente para generar iniciativas que permitan dimensionar el problema y luego tomar las conductas que correspondan para su control.

La difusión de información epidemiológica en forma oportuna, como está ocurriendo en estos casos de listeriosis perinatal, a través de los medios de difusión de la Sociedad Chilena de Infectología (revista y página WEB), contribuyen a alertar a la población y a las autoridades de salud, tomándose las medidas correspondientes para revertir el problema. Del mismo modo, instituciones como el ISP, encargado de recibir y confirmar diagnósticos microbiológicos de todo el país, debe esforzarse en mantener una información actualizada y disponible para los médicos clínicos, que permita una respuesta rápida y un análisis serio de las realidades epidemiológicas habituales y emergentes.

Los logros sanitarios en el país se consiguen con la participación de todos los integrantes de los equipos de salud, tanto públicos como privados y el interés último tiene que ser el beneficio de la población. Las autoridades regionales y ministeriales de salud han reaccionado rápidamente ante esta situación descrita respecto a $L$. monocytogenes y en conjunto con los médicos clínicos de los distintos centros asistenciales del país, están realizando un estudio epidemiológico que esperamos permitirá conocer la real magnitud del problema y dar las soluciones adecuadas.

\section{Miguel Noriega Ricalde}

Departamento Medicina Clínica Alemana, Santiago Facultad de Medicina Clínica Alemana / Universidad del Desarrollo lnoriega@alemana.cl

\section{Referencias}

1.- Anónimo. Risk assessment of Listeria monocytogenes in ready-to-eat foods: technical report. Microbiological Risk Assessment Series, No. 5. WHO, Rome, 2004. http://www.who.int/foodsafety/ publications/micro/mra listeria/en/ index.html (accedido 15/08/2008).

2.- Schlech W F 3rd, Lavigne P M, Bortolussi R A, Allen A C, Haldane E V, Wort A J, et al. Epidemic listeriosis-evidence for transmission by food. N Engl J Med 1983; 308: 203-6.

3.- Swaminathan B, Gerner-Smidt P. Epidemiology of human listeriosis. Microbes Infect 2007; 9: 1236-43.

4.- Cordano A M, Rocourt J. Occurrence of Listeria monocytogenes in food in Chile. Int J Food Microbiol 2001; 70: 175-8.

5.- Benadof D. Retrato Microbiológico:
Listeria monocytogenes. Rev Chil Infect 2008; 25: 351 (en este número).

6.- Ledermann W. Nota Histórica. En memoria de Lister. Rev Chil Infect 2008; 25: 352-7 (en este número).

7.- Rossi M L, Paiva A, Tornese M, Chianelli S, Troncoso A. Brotes de infección por Listeria monocytogenes: Una revisión de las vías que llevan a su aparición. Rev Chil Infect 2008; 25: 329-36 (en este número).

8.- Goulet V, Hedberg C, Le Monnier A, de Valk H. Increasing incidence of Listeriosis in France and other European countries. Emerg Infect Dis 2008; 14: 734-40.

9. - Larraín D, Abarzúa F, de Jourdan F, Merino P, Belmar C, García P. Infecciones por Listeria monocytogenes en mujeres embarazadas: Experiencia del Hospital Clínico de la Pontificia Universidad Católica de Chile. Rev Chil Infect 2008; 25: 337-42 (en este número).

10.- Mylonakis E, Paliou M, Hohmann E L,
Calderwood S B, Wing E J. Listeriosis during pregnancy: a case series and review of 222 cases. Medicine (Baltimore) 2002; 81: 260-9.

11.- Noriega L M, Ibáñez S, González P, Yamamoto M, Vial P. Listeria monocytogenes: Informe de un aumento de casos en mujeres embarazadas y revisión de la literatura. Rev Chil Infect 2008; 25: 343-50 (en este número).

12.- Ministerio de Agricultura. Servicio Agrícola y Ganadero. Instructivo para el muestreo de Listeria monocytogenes en preparados cárnicos listos para el consumo y productos lácteos de exportación. Chile. 2006. http://www.sag.gob.cl/pls/portal/docs/page/ pg_sag_biblioteca/bibl_exportaciones/ biblio exp pec/biblio exp pec manuales/ instructivo listeria carnicos lacteos.pdf (accedido $15 / 08 / 2008$ )

13.- Anónimo. Diario El Mercurio, 21 de agosto 2008, cuerpo C. 